\title{
Exploring Cross-Cultural Differences In Social Knowledge Creation And Exchange: A Preliminary Examination
}

John Girard, Minot State University, USA

Andy Bertsch, Minot State University, USA

\begin{abstract}
This paper chronicles an exploratory, in-progress research project that compares the findings of Hofstede's cross-cultural research with those of Forrester's Social Technographics research. The aim of the project is to determine if a relationship exists between cultural differences and social knowledge creation and exchange. Part one of the study mapped Davenport and Prusak's information and knowledge creation theories to the six components of Forrester's Social Technographics study (creators, critics, collectors, joiners, spectators, and inactives). Next, the Social Technographics results from 13 nations were compared with Hofstede's four cultural dimensions (power distance, individualism, uncertainty avoidance, masculinity). The analysis included exploring the relationship visually using 24 scatter diagrams, running correlation coefficients (Peasson's $r$ ) for each relationship, testing for significance of Pearson's $r$, and finally conducting regression analyses on each relationship. Although the authors believe that culture influences behaviours, this study did not reveal any reasonable relationships between culture and placement along the Social Technographics. However, it is possible that there exists problems in the Hofstede scales. The Hofstede scales have been highly criticized in the literature. It may be that other cross-cultural models such as GLOBE, Schwartz, Triandis, or others may yield different results. In this regard, further research is necessary. The next phase of the project will compare Social Technographics with the GLOBE project findings.
\end{abstract}

Keywords: global knowledge sharing; cross-cultural research; Social Technographics

\section{INTRODUCTION}

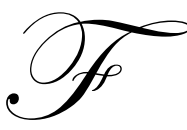

or more than 20 years, organizational leaders have strived to institutionalize effective ways to create and share organizational knowledge. A variety of concerns, including downsizing, baby boomers retirement, terrorism, the global economic crisis, and a host of other organizational challenges, have forced leaders to share knowledge with both internal and external stakeholders. Many leaders have relied on the on the solid foundation provided by several seminal works including Working Knowledge (Davenport \& Prusak, 1998), If Only We Knew What We Know (O'Dell \& Grayson, 1998), and The Knowledge Creating Company (Nonaka \& Takeuchi, 1995).

Notwithstanding the best efforts of many pioneering leaders, few organizations have attained the desired level of knowledge creation and exchange. This is certainly not due to a lack of enthusiasm or commitment of resources on the part of executives, but rather the result of technology-focused, complicated, and expensive tools, techniques, and technologies. This technological focus was further hindered by an omnipresent culture of need-toknow rather than one based on need-to-share. Together, these factors prevented the transparency necessary to achieve organizational knowledge goals. The problem becomes even more complex for global organizations.

This paper chronicles an exploratory, in-progress research project that draws together a series of recent projects with a view to understanding how global knowledge creation and exchange may be facilitated through social knowledge tools, techniques, and techniques. 


\section{LITERATURE REVIEW}

\section{Knowledge Management Generations}

In A Leader's Guide to Knowledge Management, the authors suggested that many first-generation knowledge management projects were based on collecting and classifying information (John P. Girard \& JoAnn L. Girard, 2009). The belief seemed to be that if we developed huge, centralized, IT-based repositories of artifacts, then stakeholders would serve themselves. Unfortunately, this approach never delivered the promised user-friendly access but rather resulted in many very expensive partial databases of little value.

Second-generation knowledge management projects, they argued, shifted the focus to codifying tacit knowledge and combining explicit knowledge to create new knowledge. This approach seemed plausible in theory; however, quickly it became apparent that codifying tacit knowledge was difficult and very expensive, both in terms of time and money. Further exacerbating the challenge was the issue of information overload that resulted from the combination efforts.

Finally, Girard and Girard (2009) suggested that today we are seeing some very promising results from third-generation knowledge projects, which focus on connecting people and facilitating collaboration. Their projects focus on the social side of knowledge creation and exchange, referred to as Social Knowledge. Some organizations are now reaping the benefits of using social media tools such as wikis for collaboration and knowledge-sharing and commercial social networking tools, such as Facebook, LinkedIn, or Twitter for connecting people. These emerging tools and techniques provide flexible, agile, and intuitive solutions for connecting people with people and facilitating coordination, communication, and collaboration.

\section{Social Technographics}

A characteristic of the first decade of the $21^{\text {st }}$ century is the emerging power of everyday people. In their book Groundswell: Winning in a World Transformed by Social Technologies, Forrester analysts Charlene Li and Josh Bernoff (Li \& Bernoff, 2008) describe part of this trend as a groundswell, which they define as "a social trend in which people use technologies to get the things they need from each other, rather than from traditional institutions like corporations" (p. 9). The groundswell may be useful in considering cross-cultural differences and the resultant impact on third generation knowledge projects.

The groundswell concept arms ordinary people with unparalleled power, especially people that gather together and create communities. For centuries, groups of passionate people have yearned for the opportunity to influence decision makers. Of course, there have been many times in history when large groups congregated to spark change. However, the logistics with massing large groups can be very cumbersome, expensive, and difficult to communicate. The advent of Web 2.0, a World Wide Web based on collaboration rather than content, eliminated many of these obstacles. In their book Wikinomics: How Mass Collaboration Changes Everything, the authors describe how a low-cost collaborative infrastructure is empowering the many with "weapons of mass collaboration" (Tapscott \& Williams, 2006, p. 11). Tapscott and Williams (2006) warn these weapons support a new level of collaboration that will turn the economy upside down and may well facilitate the destruction of organizations who fail to adjust.

Li and Bernoff developed the Forrester's Social Technographics ${ }^{\circledR}$ to categorize consumers based on their social computing habits. They use a ladder analogy with six rungs, which correlates to the six levels of social computing. Their model considers how adult Internet users utilize the Internet "to get the things they need from each other, rather than from traditional institutions like corporations" (Li \& Bernoff, 2008, p. 9). Li and Bernoff's definitions of each dimension are in Table 1. 
Table 1: Social Technographics Dimensions

Adapted from (Li \& Bernoff, 2008)

\begin{tabular}{|l|l|}
\hline \multicolumn{1}{|c|}{ Dimension } & \multicolumn{1}{c|}{ Li and Bernoff's Definition } \\
\hline Creators & Creators make social content go. They write or upload video, music, or text. \\
\hline Critics & $\begin{array}{l}\text { Critics respond to content from other. They post reviews, comment on blogs, participate in forums, and edit } \\
\text { wiki articles. }\end{array}$ \\
\hline Collectors & Collectors organize content for themselves or others using RSS feeds, tags, and voting sites like Digg.com. \\
\hline Joiners & Joiners connect in social networks like MySpace and Facebook. \\
\hline Spectators & Spectators consume social content including blogs, user-generated video, podcasts, forums, or reviews. \\
\hline Inactives & Inactives neither create nor consume social content of any kind. \\
\hline
\end{tabular}

Although the Social Technographics concept was originally envisaged to model consumer behaviour from a marketing lens, much can be learned from a knowledge sharing point of view. Internet users in five of the dimensions are actively creating and exchanging knowledge in the social space. Although the scope of this paper precludes a detailed analysis of information and knowledge creation, a brief overview is prudent. A seminal work in the field is Davenport and Prusak's (1998) Working Knowledge, in which they articulated five major ways in which data could be transformed into information. These are summarised in Table 2.

Table 2: Data to Information Creation Tasks

Adapted from Davenport and Prusak (1998)

\begin{tabular}{|l|l|}
\hline \multicolumn{1}{|c|}{ Dimension } & \multicolumn{1}{c|}{ Transformation Task } \\
\hline Context & Put the data into context by communicating the reason for gathering the data \\
\hline Categorize & Categorize the data by describing the breakdown or the essential components of the data \\
\hline Calculate & Mathematically or statistically calculate the data \\
\hline Correct & Correct errors in previously reported data \\
\hline Condense & Condense the data by providing a summary instead of the entire collection of data \\
\hline
\end{tabular}

Similarly, Davenport and Prusak (1998) described how information may metamorphose into knowledge through a series of activities that increase its value as summarized in Table 3.

Table 3: Information to Knowledge Creation Tasks

Adapted from Davenport and Prusak (1998)

\begin{tabular}{|l|l|}
\hline \multicolumn{1}{|c|}{ Dimension } & \multicolumn{1}{c|}{ Transformation Task } \\
\hline Compare & $\begin{array}{l}\text { Compare information with previous information, primarily to determine what has changed in a } \\
\text { particular situation }\end{array}$ \\
\hline Consequences & Determine the consequences or repercussions of this information on decisions \\
\hline Connects & Consider how this information connects or correlates to other information \\
\hline Conversation & Through conversation one may conclude what people think about the information \\
\hline
\end{tabular}

By combing the work of Davenport and Prusak with that of Li and Bernoff, one may deduce that the Social Technographics components cater to knowledge creation and exchange in the social dimension. A brief summary is presented Table 4.

Table 4: Social Technographics Dimensions Adapted from Li and Bernoff (2008)

\begin{tabular}{|l|l|}
\hline \multicolumn{1}{|c|}{ Dimension } & \multicolumn{1}{c|}{ Knowledge Sharing Activity } \\
\hline Creators & $\begin{array}{l}\text { Creators produce and share information and knowledge that is freely available to other users, the } \\
\text { quintessence of need-to-share. }\end{array}$ \\
\hline Critics & $\begin{array}{l}\text { Critics add value to the data, information and knowledge shared by creators. Their feedback, comments, } \\
\text { and corrections often facilitate the metamorphosis of data to information or information to knowledge } \\
\text { thorough conversation, connections, and comparison. }\end{array}$ \\
\hline Collectors & $\begin{array}{l}\text { Collectors provide access and provide the opportunity for other users to compare and connect } \\
\text { information. }\end{array}$ \\
\hline Joiners & Online communities facilitate conversation. \\
\hline Spectators & Spectators consume the information and knowledge created by others. \\
\hline Inactives & Inactives do not create or exchange social knowledge \\
\hline
\end{tabular}


The clear connection between the Social Technographics and Davenport and Prusak's knowledge creation processes provides a foundation from which we may explore the global environment. Of particular interest to this project are different levels of social computing by nation. For example, according to Li and Bernoff (2008), 34\% of adult Japanese Internet users are classified as "creators" compared with on $9 \%$ of adult German Internet users. To date, Social Technographics data has been collected for 13 nations that will be considered later in the paper.

\section{Hofstede}

Geert Hofstede (1980a), a pioneering researcher in the domain cross-cultural research, argued there are four key dimensions of cultural differences: power distance, individualism, uncertainty avoidance, masculinity. Hofstede's original publication (1980a) was based on 116,000 surveys from 88,000 employees of IBM subsidiaries from 72 societies. However, only 40 countries were included in his published work; due, in part, because he only included societies that had more than 50 respondents. From this reduced sample of 40 countries, Hofstede identified the original four cultural value dimensions (sans the Long Term Orientation dimension); later the data was expanded to 50 countries and the fifth dimension, Long Term Orientation (LTO), was added (Cullen and Parboteeah 2008; Hofstede 1980, 2001; Hofstede and Bond 1988; Kirkman et al. 2006).

Hofstede's 1980 publication illustrating the concept of culture and its impact on management and business operations was significant. His work has become a heavily replicated and referenced cultural model. As of 2001, there had been 140 replications, and between January, 2000 and December, 2005, his work appeared as a reference in nearly 1,400 journal articles (Hofstede, 2001; Holt, 2007). Flaws in some of the replications have been identified by Hofstede himself as he is critical of replications that do not match the samples from each society, are small in size (small $\mathrm{n}$ from each society), or compare too few societies (Hofstede, 1996, 2001). Hofstede's five dimensions are summarized in Table 5. Details for each dimension will be further explored in sections to follow.

Table 5: Hofstede's Cultural Dimensions Adapted from Hofstede (Hofstede, 1980a, 2001)

\begin{tabular}{|l|l|}
\hline \multicolumn{1}{|c|}{ Dimension } & \multicolumn{1}{c|}{ Continuum } \\
\hline Power Distance Index (PDI) & Low Power Distance vs. High Power Distance \\
\hline Uncertainty Avoidance Index (UAI) & Low Uncertainty Avoidance vs. High Uncertainty Avoidance \\
\hline Individualism (IDV) & Individualism vs. Collectivism \\
\hline Masculinity (MAS) & Masculinity vs. Femininity \\
\hline Long-Term Time Orientation (LTO) & Long-term orientation vs. Short-term orientation \\
\hline
\end{tabular}

Kluckhohn and Strodtbeck's influence on future cultural researchers is evident in citations and reference pages. Hofstede himself describes his own 30-year quest for cultural dimensions which define how all societies face the same basic problems, coming up with different solutions from one society to the next (Hofstede, 1996). This 'problems-solutions' concept was anthropologically grounded and offered by Kluckhohn and Strodtbeck some 35 years earlier.

Some are critical of Hofstede's methodology and findings. Hofstede based his work on surveys of IBM managers in 40 different countries. This alone has spurred a plethora of outcries. To some, a study of only one organization cannot be generalized onto the entire population of a society. The debate of whether nations are the appropriate units of measurement directly challenges Hofstede's practice of measuring the value systems of managers from a single organization and subsequent inference onto the national culture (e.g. ecological fallacy and reverse ecological fallacy). In addition, there are those who challenge the timeliness of Hofstede's collection of data (1967-1969, and 1971-1973) and whether the data is obsolete. Others have been critical of any study that uses survey instruments to assess cultures. Additionally, the debate continues relative to Hofstede's model having only five dimensions as some researchers claim this is too few. Others have found that cultural differences exist between countries within a specific culture map or cluster even though Hofstede had grouped them as culturally similar. The framework offered by Hofstede cannot readily reconcile the inconsistencies within some culture map groupings (Darlington 1996; Dowling and Nagel 1986; Hanges and Dickson 2004; Harrison and Huntington 2000; Holt 2007; House et al. 2004; Javidan and House 2001; Javidan et al. 2006; Kirkman et al. 2006; McFarlin and Sweeny 2006; Schein 1985, 1992, 2004; Shweder 2000; Sondergaard 1994). 


\section{METHODOLOGY}

Exploratory research is useful when the problem needs to be defined more precisely, when little theory exists concerning the research question and context, and specific courses of action into how to approach or solve the research problem need to be explored (J. F. Hair, Jr., Babin, Money, \& Samouel, 2003; Malhotra, 2007; Zikmund \& Babin, 2007). The primary objective of exploratory research is to provide insight into the problem confronting the researcher. The primary research question is ambiguous and the researcher seeks to discover new information (Zikmund \& Babin, 2007). The sample many times is unrepresentative and is based on convenience. Although the data can be qualitative during exploratory research, a quantitative survey is also an acceptable method of data collection (Malhotra, 2007). Often, findings of exploratory research are tentative and are used to guide new and conclusive research designs (J. F. Hair, Jr., et al., 2003; Malhotra, 2007; Zikmund \& Babin, 2007).

This study seeks to analyze the relationship between cultural values and Forrester's Social Technographics ${ }^{\circledR}$ scale. As stated in the literature review, this study has chosen Hofstede's cultural model to study the effects, if any, on predicting a country's position along the various rungs of the Social Technographics. Statistical techniques used to measure the association and potential relationships between two or more variables include correlation and regression analyses (Harnett \& Horrell, 1998; Lind, Marchal, \& Wathen, 2010). In this regard, this study is exploring the relationship between culture and placement on the Forrester scale. Culture will be treated as the independent variable used to determine a country's placement on the Social Technographics which will be considered the dependent variable. The steps that will be followed to explore these relationships follows herein (Harnett \& Horrell, 1998; Lind, et al., 2010):

1. Scatter Diagrams. The authors will produce scatter diagrams to visually explore possible relationships.

2. Pearson's Coefficient of Correlation. If appropriately linear, Pearson's $r$ will be used to determine the strength of relationship. Caution will be in order as correlation is not the same as causation (for an example of such discussion, see Lind (2010, p. 462)).

3. Test for significance of Pearson's $r$.

4. Regression analysis in order to determine the reasonableness of predicting a country's placement along the Forrester scale.

In conclusion, this study will employ an exploratory research design aimed at exploring the relationships between cultural dimension variables (independent variables) and a country's placement on the Forrester scales (dependent variables). The authors have chosen correlation and regression techniques to explore these relationships.

\section{ANALYSIS}

To date, there are thirteen (13) countries where data exists in the Forrester model. Using Hofstde's most recently reported dimension scores along the PDI, UAI, IDV, and MAS scales, Table 6 was developed.

Table 6: Country Scores for Forrester and Hofstede Scales

\begin{tabular}{|c|c|c|c|c|c|c|c|c|c|c|}
\hline Country & Creators & Critics & Collectors & Joiners & Spectators & Inactives & PDI & UAI & IDV & $\overline{\text { MAS }}$ \\
\hline US & 24 & 37 & 21 & 51 & 73 & 18 & 40 & 46 & 91 & 62 \\
\hline Canada & 18 & 29 & 17 & 57 & 64 & 21 & 39 & 48 & 80 & 52 \\
\hline UK & 15 & 21 & 6 & 38 & 50 & 37 & 35 & 35 & 89 & 66 \\
\hline France & 12 & 19 & 6 & 24 & 51 & 40 & 68 & 86 & 71 & 43 \\
\hline Germany & 9 & 12 & 4 & 21 & 38 & 52 & 35 & 65 & 67 & 66 \\
\hline Italy & 29 & 25 & 7 & 33 & 52 & 36 & 50 & 76 & 70 & 75 \\
\hline Metro China & 44 & 46 & 37 & 32 & 79 & 17 & 80 & 20 & 66 & 30 \\
\hline Japan & 34 & 30 & 11 & 26 & 69 & 23 & 54 & 92 & 46 & 95 \\
\hline South Korea & 49 & 46 & 19 & 48 & 76 & 9 & 60 & 18 & 39 & 85 \\
\hline Australia & 23 & 31 & 14 & 50 & 64 & 22 & 36 & 51 & 90 & 61 \\
\hline Spain & 15 & 21 & 8 & 24 & 56 & 38 & 57 & 86 & 51 & 42 \\
\hline Netherlands & 20 & 20 & 8 & 38 & 64 & 27 & 38 & 53 & 80 & 14 \\
\hline Sweden & 14 & 21 & 8 & 37 & 59 & 32 & 31 & 29 & 71 & 5 \\
\hline
\end{tabular}


As explained earlier, the first step in exploring the relationships between the variables (columns) provided in Table 6 is to create scatter diagrams and visually explore the data for apparent relationships (Lind, et al., 2010). This required 24 scatter diagrams (4 Hofstede Cultural Scales X 6 Forrester Technographic Scales). After visually analyzing the 24 diagrams, there were no apparent relationships between the variables. The second step as discussed in the methodology section above is to run correlation coefficients (Pearson's $r$ ) for each relationship. Table 7 illustrates the correlation coefficients for and between each variable.

Table 7: Correlation Coefficients

\begin{tabular}{|l|c|c|c|c|c|c|}
\hline & Creators & Critics & Collectors & Joiners & Spectators & Inactives \\
\hline PDI & 0.5736 & 0.4994 & 0.5276 & -0.3520 & 0.3928 & -0.2520 \\
\hline UAI & -0.3907 & -0.5423 & -0.5646 & -0.5728 & -0.4645 & 0.5264 \\
\hline IDV & -0.4827 & -0.2245 & -0.0435 & 0.4311 & -0.1771 & 0.1135 \\
\hline MAS & 0.3622 & 0.2444 & -0.0511 & 0.0452 & 0.0065 & -0.1283 \\
\hline
\end{tabular}

In reviewing Table 7, one realizes there are many weakly correlated relationships between the Hofstede scale scores and the Forrester scales. Further to the steps outlined in the Methodology section above, a test of significance for each of the correlations in Table 7 is in order. Table 8 illustrates the respective t-statistic for each correlation coefficient.

Table 8: Correlation Coefficients and Associated t-Scores

\begin{tabular}{|l|c|c|c|c|c|c|}
\hline & Creators & Critics & Collectors & Joiners & Spectators & Inactives \\
\hline \multirow{2}{*}{ PDI } & 0.5736 & 0.4994 & 0.5276 & -0.3520 & 0.3928 & -0.2520 \\
& $\mathrm{t}=2.32$ & $\mathrm{t}=1.91$ & $\mathrm{t}=2.06$ & $\mathrm{t}=-1.25$ & $\mathrm{t}=1.42$ & $\mathrm{t}=-0.86$ \\
\hline \multirow{2}{*}{ UAI } & -0.3907 & -0.5423 & -0.5646 & -0.5728 & -0.4645 & 0.5264 \\
& $\mathrm{t}=-1.41$ & $\mathrm{t}=-2.14$ & $\mathrm{t}=-2.27$ & $\mathrm{t}=-2.32$ & $\mathrm{t}=-1.74$ & $\mathrm{t}=2.05$ \\
\hline \multirow{2}{*}{ IDV } & -0.4827 & -0.2245 & -0.0435 & 0.4311 & -0.1771 & 0.1135 \\
& $\mathrm{t}=-1.83$ & $\mathrm{t}=-0.76$ & $\mathrm{t}=-0.14$ & $\mathrm{t}=1.58$ & $\mathrm{t}=-0.60$ & $\mathrm{t}=0.38$ \\
\hline \multirow{2}{*}{ MAS } & 0.3622 & 0.2444 & -0.0511 & 0.0452 & 0.0065 & -0.1283 \\
& $\mathrm{t}=1.29$ & $\mathrm{t}=0.84$ & $\mathrm{t}=-0.17$ & $\mathrm{t}=0.15$ & $\mathrm{t}=0.02$ & $\mathrm{t}=-0.43$ \\
\hline
\end{tabular}

Using a standard t-test with degrees of freedom of n-2 (Lind, et al., 2010), the critical t-value is \pm 2.20 for $\mathrm{p}<0.05$. As a result, none of the Hofstede dimensions are solely and significantly correlated with a country's placement on the Social Technographics. In fact, of the correlations, only the following were deemed to be statistically significant:

1. PDI to Creators, $\mathrm{r}=0.5736, \mathrm{t}=2.32, \mathrm{p}<0.05$

2. UAI to Collectors, $\mathrm{r}=-0.5646 . \mathrm{t}=-2.27, \mathrm{p}<0.05$

3. UAI to Joiners, $\mathrm{r}=-0.5728, \mathrm{t}=-2.32, \mathrm{p}<0.05$

As a last step, regression analyses were ran on each of the 24 relationships contained in Tables 7 and 8 . Table 9 was created to illustrate the $\mathrm{R}^{2}$ value and the standard error for each relationship.

Hair, et al. (2006) suggests that $\mathrm{R}^{2}$ values less than 0.50 result in less than acceptable models. With an $\mathrm{R}^{2}$ value less than 0.50 , more than 0.50 of the variance in the dependent variable is attributed to spurious variables or error (Joseph F. Hair, Jr., et al., 2006). With this in mind, none of the Hofstede cultural dimension scores are reliable in predicting a country's placement on the Social Technographics. Additionally, the standard error values are problematic in all of the above relationships. With these unreasonably high values for standard error compared to the actual values along each rung of the Social Technographics, there is very little opportunity to reasonably predict a country's placement on the Social Technographics. 
Table 9: Correlation Coefficients with t-Scores, $\mathbf{R}^{2}$ values, and Standard Error

\begin{tabular}{|c|c|c|c|c|c|c|}
\hline & Creators & Critics & Collectors & Joiners & Spectators & Inactives \\
\hline PDI & $\begin{array}{c}0.5736 \\
t=2.32 \\
R^{2}=0.33 \\
S E=11\end{array}$ & $\begin{array}{c}0.4994 \\
\mathrm{t}=1.91 \\
\mathrm{R}^{2}=0.25 \\
\mathrm{SE}=9\end{array}$ & $\begin{array}{c}0.5276 \\
t=2.06 \\
R^{2}=0.28 \\
S E=8\end{array}$ & $\begin{array}{c}-0.3520 \\
t=-1.25 \\
R^{2}=0.12 \\
S E=11\end{array}$ & $\begin{array}{c}0.3928 \\
t=1.42 \\
R^{2}=0.15 \\
S E=11\end{array}$ & $\begin{array}{c}-0.2520 \\
t=-0.86 \\
R^{2}=0.06 \\
S E=12\end{array}$ \\
\hline UAI & $\begin{array}{c}-0.3907 \\
t=-1.41 \\
R^{2}=0.15 \\
S E=12\end{array}$ & $\begin{array}{c}-0.5423 \\
t=-2.14 \\
R^{2}=0.29 \\
S E=9\end{array}$ & $\begin{array}{c}-0.5646 \\
t=-2.27 \\
R^{2}=0.32 \\
S E=8\end{array}$ & $\begin{array}{c}-0.5728 \\
t=-2.32 \\
R^{2}=0.33 \\
S E=10\end{array}$ & $\begin{array}{c}-0.4645 \\
t=-1.74 \\
R^{2}=0.22 \\
S E=11\end{array}$ & $\begin{array}{c}0.5264 \\
t=2.05 \\
R^{2}=0.28 \\
S E=10\end{array}$ \\
\hline IDV & $\begin{array}{c}-0.4827 \\
\mathrm{t}=-1.83 \\
\mathrm{R}^{2}=0.23 \\
\mathrm{SE}=11\end{array}$ & $\begin{array}{c}-0.2245 \\
t=-0.76 \\
R^{2}=0.05 \\
S E=11\end{array}$ & $\begin{array}{c}-0.0435 \\
t=-0.14 \\
R^{2}=0.00 \\
S E=9\end{array}$ & $\begin{array}{c}0.4311 \\
t=1.58 \\
R^{2}=0.19 \\
S E=11\end{array}$ & $\begin{array}{c}-0.1771 \\
\mathrm{t}=-0.60 \\
\mathrm{R}^{2}=0.03 \\
\mathrm{SE}=12\end{array}$ & $\begin{array}{c}0.1135 \\
t=0.38 \\
R^{2}=0.01 \\
S E=12\end{array}$ \\
\hline MAS & $\begin{array}{c}0.3622 \\
t=1.29 \\
R^{2}=0.13 \\
S E=12\end{array}$ & $\begin{array}{c}0.2444 \\
t=0.84 \\
R^{2}=0.06 \\
S E=11\end{array}$ & $\begin{array}{c}-0.0511 \\
t=-0.17 \\
R^{2}=0.00 \\
S E=9\end{array}$ & $\begin{array}{c}0.0452 \\
t=0.15 \\
R^{2}=0.00 \\
S E=12\end{array}$ & $\begin{array}{c}0.0065 \\
t=0.02 \\
R^{2}=0.00 \\
S E=12\end{array}$ & $\begin{array}{c}-0.1283 \\
t=-0.43 \\
R^{2}=0.02 \\
S E=12\end{array}$ \\
\hline
\end{tabular}

\section{CONCLUSIONS}

Although the authors believe that culture influences behaviours, this study did not reveal any reasonable relationships between culture and placement along the Social Technographics. However, it is possible that there exists problems in the Hofstede scales. The Hofstede scales have been highly criticized in the literature (for an example of such criticism, see McSweeny (2002) and Sivakumar \& Nakata (2001)). It may be that other crosscultural models such as GLOBE, Schwartz, Triandis, or others may yield different results. In this regard, further research is necessary.

\section{AUTHOR INFORMATION}

John Girard, Ph.D. is a professor at Minot State University where he teaches graduate and undergraduate business classes. John's current research interests include knowledge management, social media, virtual business, online education, and globalization. John is founder and Chief Knowledge Strategist of Sagology (www.sagology.com), a firm dedicated to connecting people with people to facilitate collaboration, learning, and knowledge sharing through keynotes, workshops, and consulting. The Council of College Faculties elected John the 2010 - 11 faculty advisor to the State Board of Higher Education. In 2004, John retired from the Canadian Forces at the rank of Lieutenant-Colonel after 24 years in uniform.

Andy Bertsch holds a Doctor of Business Administration (DBA) degree and an Advanced Postgraduate Diploma in Management Consultancy (APDMC) from the Henley Management College in England. Henley is an elite business school that holds triple accreditation including AACSB. With over 20 years of experience in executive management, management consultancy, and leadership development, Andy has actively guided or participated with organizations, education institutions, and government agencies as they have undergone transformation through environmental assessments, mission analysis, visioning, strategic analyses and formulation, and implementation. Andy actively researches and consultants in the fields of culture, leadership, strategic planning and implementation.

\section{REFERENCES}

1. Davenport, T. H., \& Prusak, L. (1998). Working knowledge : how organizations manage what they know. Boston, Mass: Harvard Business School Press.

2. Girard, J. P., \& Girard, J. L. (2009). A Leader's Guide to Knowledge Management: Drawing on the Past to Enhance Future Performance. New York: Business Expert Press.

3. Hair, J. F., Jr., Babin, B., Money, A. H., \& Samouel, P. (2003). Essentials of Business Research Methods. New Jersey: Wiley. 
4. Hair, J. F., Jr., Black, W. C., Babin, B. J., Anderson, R. E., \& Tatham, R., L. (2006). Multivariate Data Analysis (6th ed.). Upper Saddle River, NJ: Pearson Prentice Hall.

5. Harnett, D. L., \& Horrell, J. F. (1998). Data, Statistics, and Decision Models. New York: Wiley.

6. Hofstede, G. (1980). Culture's Consequences: International Differences in Work-Related Values. London: Sage.

7. Hofstede, G. (1996). Images of Europe: Past, Present, and Future. In M. Warner \& P. Joynt (Eds.), Managing Across Cultures: Issues and Perspectives. Boston, MA: International Thomson Business Press.

8. Hofstede, G. (2001). Culture's Consequences: Comparing Values, Behaviors, Institutions, and Organizations Across Nations. London: Sage Publications.

9. Holt, G. (2007). Organizational Culture and Performance: A Survey in Norway and Pakistan. Henley Management College, Henley-on-Thames.

10. Li, C., \& Bernoff, J. (2008). Groundswell : winning in a world transformed by social technologies. Boston, Mass.: Harvard Business Press.

11. Lind, D. A., Marchal, W. G., \& Wathen, S. A. (2010). Statistical Techniques in Business \& Economics (14th ed.). New York: McGraw Hill Irwin.

12. Malhotra, N. K. (2007). Marketing Research: An Applied Orientation (5th ed. ed.). Upper Saddle River, NJ: Pearson Prentice Hall.

13. McSweeney, B. (2002). Hofstede's model of national cultural differences and their consequences:A triumph of faith - a failure of analysis. Human Relations, 55 (1)(1), 89-118.

14. Nonaka, I., \& Takeuchi, H. (1995). The knowledge-creating company: how Japanese companies create the dynamics of innovation. New York: Oxford University Press.

15. O'Dell, C., \& Grayson, C. J. (1998). If only we knew what we know: identification and transfer of internal best practices. California Management Review, 40(3), 154-174.

16. Sivakumar, K., \& Nakata, C. (2001). The Stampede Toward Hofstede's Framework: Avoiding the Sample Design Pit in Cros-Cultural Research. Journal of International Business Studies, 32(3), 555-574.

17. Tapscott, D., \& Williams, A. D. (2006). Wikinomics : how mass collaboration changes everything. New York: Portfolio.

18. Zikmund, A. G., \& Babin, B. J. (2007). Exploring Marketing Research (9th ed. ed.). Mason, OH: Thomson South-western. 